\title{
Microstructural Evolution of Vacuum Die-Cast AZ91D Magnesium Alloy during Solution Treatment
}

\author{
Qingliang Wang ${ }^{1, *}$, Yi $\operatorname{Han}^{1}$ and Shoumei Xiong ${ }^{2}$ \\ ${ }^{1}$ National Engineering Research Center for Equipment and Technology of Cold Strip Rolling, Yanshan University, \\ Qinhuangdao 066004, China \\ ${ }^{2}$ School of Materials Science and Engineering, Tsinghua University, Beijing 100084, China
}

\begin{abstract}
The microstructural evolution in different regions on the cross section of AZ91D vacuum die castings during solution treatment, especially during the early stage, was investigated. Optical microscope and scanning electron microscope were employed for the microstructure observation. The results exhibited that the supersaturated $\alpha$-Mg solution located in the grain boundaries first dissolved. The $\beta$-Mg ${ }_{17} \mathrm{Al}_{12}$ particles in the surface layer had a slower dissolution speed when compared to those in the central region, and the remaining $\beta$-Mg $\mathrm{Al}_{17} \mathrm{Al}_{12}$ particles in the surface layer could effectively restrain the grain growth during the early stage. In the central region, due to the mergence of neighbouring dendrite arms of the same ESC, most remaining $\beta-\mathrm{Mg}_{17} \mathrm{Al}_{12}$ particles were encapsulated in the relatively large near globular $\alpha-\mathrm{Mg}$ grains evolved from the ESCs. The shrinkage porosities concentrated in the segregation band could effectively restrain the grain growth, causing the segregation band maintained a fine microstructure during the solution treatment. [doi:10.2320/matertrans.MT-M2019140]
\end{abstract}

(Received May 13, 2019; Accepted July 1, 2019; Published September 25, 2019)

Keywords: vacuum die casting, solution treatment, microstructural evolution, AZ91D

\section{Introduction}

As the lightest metal, magnesium alloys are increasingly being used for structural components, particularly in the automobile industry. ${ }^{1)}$ High-pressure die casting (HPDC) is the major manufacturing process for magnesium products, which is of high efficiency and low cost. Currently, AZ91 is the most widely used die casting magnesium alloy and has a good combination of mechanical properties at room temperature, castability and corrosion resistance. ${ }^{2,3)}$

In HPDC process, solidification begins when superheated metal is poured into the shot sleeve. When the plunger moves forward, a mixture of externally solidified crystals (ESCs) and melt is injected into the die cavity where rapid solidification takes place. ${ }^{4)}$ The unique processing technology results in distinctive microstructural features for HPDC castings, such as the narrow bands of positive macrosegregation that commonly follow the outer contour of components, ${ }^{5,6)}$ and two well differentiated regions on the casting cross section: a surface layer with a fine grain microstructure and a center region with a coarser grain microstructure. ${ }^{4,7,8)}$ Besides, the conventional HPDC castings generally contain a substantial amount of gas porosity due to gas entrapment during die filling. ${ }^{9)}$ Such gas porosity not only adversely affects the mechanical properties and limits the applications of the castings, but also denies the opportunity for enhancement by subsequent heat treatment. ${ }^{10,11)}$ Vacuum die casting is an effective way in reducing the gas porosity level in castings. By creating a lower than atmospheric pressure in the shot sleeve and die cavity, much less gas would be entrapped in the molten metal during the vacuum die casting process. ${ }^{12)}$ The low gas porosity level induces relatively high mechanical properties, and moreover, it makes the further improvement of the mechanical properties available through subsequent heat treatment.

*Corresponding author, E-mail: wql_456@163.com
However, the research reports on the application of heat treatment to vacuum die-cast AZ91 alloy are very limited to date. In existing literature, vacuum die-cast AZ91 alloy is usually subjected to a T6 heat treatment, ${ }^{13-16)}$ which involves two separate steps, typically solution treatment at $\sim 420^{\circ} \mathrm{C}$ for $16-24 \mathrm{~h}$ and subsequent aging at $168^{\circ} \mathrm{C}$ for $16 \mathrm{~h}$. Solution treatment causes the $\beta$-phase to dissolve and a super-saturated solid solution can be formed after the following quenching. During aging, the $\beta$-phase precipitates out from the supersaturated solid solution in two competitive modes, discontinuous precipitation and continuous precipitation, depending on the aging temperature. The main concerns of these studies are to investigate the precipitation of $\beta$-phase and concomitant age hardening effect during aging. Little attention has been paid on the microstructural evolution during solution treatment, especially during the early stage. Considering the diversity of the microstructure in vacuum die castings and the significant impact of solution treatment on the subsequent aging effect, a comprehensive study on the microstructural evolution of vacuum die-cast AZ91 alloy during solution treatment is badly needed. Besides, no satisfactory combination of mechanical properties has been achieved for vacuum die-cast AZ91 alloy through existing heat treatment schedules. ${ }^{13-18)}$ The examination of the microstructural evolution of vacuum die-cast AZ91 alloy during solution treatment will be helpful to develop a new heat treatment schedule for achieving an optimized combination of mechanical properties. In this paper, the microstructural evolution in different regions on the cross section of AZ91D vacuum die castings during solution treatment, especially during the early stage, will be scrutinized.

\section{Experimental Procedure}

The composition of the AZ91D alloy used in the present study was Mg-9.02 wt\%Al-0.66 wt\%Zn-0.20 wt\%Mn-0.03 wt $\% \mathrm{Si}-0.001 \mathrm{wt} \% \mathrm{Fe}-0.002 \mathrm{wt} \% \mathrm{Cu}$. The alloy was cast in a TOYO BD-350V5 cold chamber die casting machine 


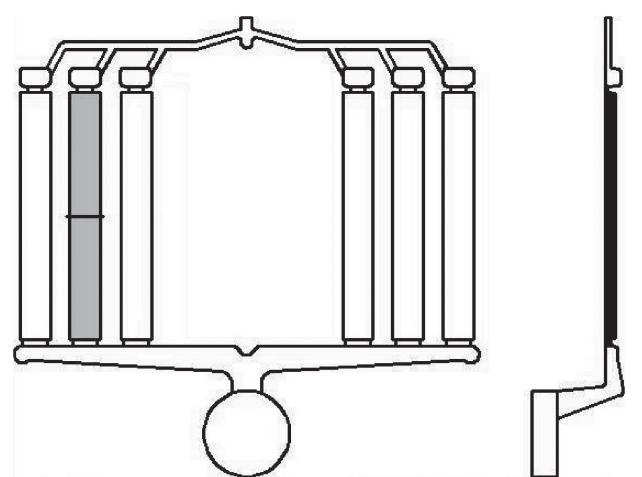

Fig. 1 Configuration of plate-shaped casting with investigated position indicated. The plate marked with gray color was taken as samples for solution treatment and the line in the middle of the plate indicates the cross section for microstructural examination.

incorporated with a self-improved TOYO vacuum system. Figure 1 shows the configuration of the plate-shaped castings made on the machine. From left to right, the thicknesses of the six plates in the casting are $6.25 \mathrm{~mm}, 3.75 \mathrm{~mm}, 1.25 \mathrm{~mm}$, $2.5 \mathrm{~mm}, 5 \mathrm{~mm}$ and $7.5 \mathrm{~mm}$, respectively. The six plates have the same length of $210 \mathrm{~mm}$. A constant slow shot speed $0.15 \mathrm{~m} / \mathrm{s}$ was used in this study. Table 1 lists some other important process parameters used in the experiments which were preset in the machine. The plates with thickness of $5 \mathrm{~mm}$ in the vacuum die castings were taken as samples. In the present study, the solution treatment was carried out at $413^{\circ} \mathrm{C}$ for $20 \mathrm{~h}$, in air with the protection of magnesia powders on the surface of the samples. In order to study the microstructural evolution of the vacuum die castings at the early stage of the solution treatment, some samples were taken out after solution treated for less than $1 \mathrm{~h}$. The samples were then quenched in water.

Specimens were cut from the middle parts of the solution treated samples along the transverse direction, as shown in Fig. 1, for microstructural characterization, which was carried out using optical microscopy (OM) and scanning electron microscopy (SEM). The specimens for OM and SEM were prepared by the standard technique of grinding and polishing, followed by etching with an acetic nitric etch. A Zeiss optical microscope was utilized for the OM and quantitative metallography. At least three micrographs were analyzed for each measurement. A Jeol JXA-840A scanning electron microscopy, equipped with energy dispersive spectroscopy (EDS), was used to perform the SEM examinations.

\section{Results and Discussion}

\subsection{As-cast microstructural features of vacuum die-cast AZ91D alloy}

Figure 2 shows the typical cross sectional microstructure of the as-cast AZ91D alloy produced by the vacuum die

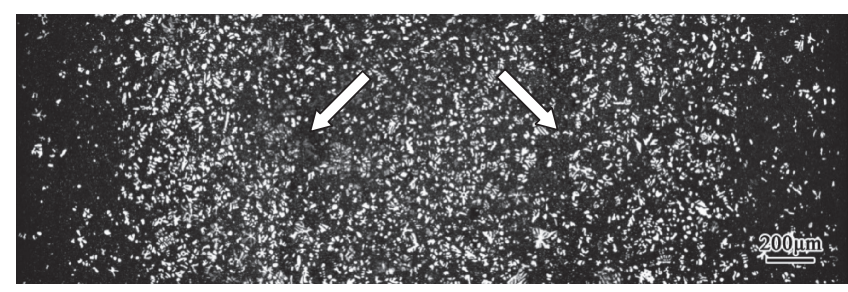

Fig. 2 Optical cross sectional micrograph showing the microstructural distribution in the as-cast AZ91D alloy produced by vacuum die casting process.

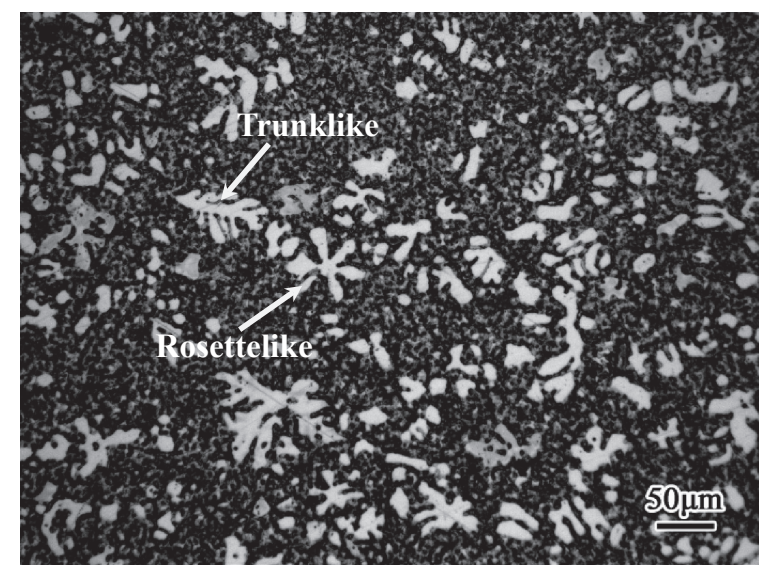

Fig. 3 Optical micrograph taken from the central region on the casting cross section showing the different morphologies of ESCs in the as-cast AZ91D alloy produced by vacuum die casting process.

casting process. One of the most distinctive microstructural features observed in the microstructure is the presence of relatively large primary grains. These large $\alpha-\mathrm{Mg}$ particles, commonly termed externally solidified crystals (ESCs), originate in the shot sleeve and are subsequently injected into the die cavity with the liquid metal. Due to the shear flow effects, ${ }^{19)}$ the ESCs migrate to the center of the die cavity during the die filling, resulting in a central region with a much higher density of ESCs compared to that in the surface layer as shown in Fig. 2. Concerning the morphologies of the ESCs, these are found to be rosettelike, trunklike, partially or almost fully globular in shape (Fig. 3).

Another distinct phenomenon observed in Fig. 2 is the appearance of segregation bands (indicated by arrows in Fig. 2) inside the castings, which contain a lower density of ESCs than the adjacent regions. In the solidification process, the segregation bands reach the end of solidification later than adjacent regions, which causes that the shrinkage porosity is prone to form in the segregation bands. As a result, the segregation bands always contain a higher fraction of shrinkage porosity than the adjacent regions. ${ }^{5,6)}$

The microstructural features in the as-cast AZ91D alloy produced by vacuum die casting process are shown in Fig. 4.

Table 1 Some important process parameters used in die casting.

\begin{tabular}{ccccc}
\hline $\begin{array}{c}\text { Pouring } \\
\text { temperature }(\mathrm{K})\end{array}$ & $\begin{array}{c}\text { Die temperature } \\
(\mathrm{K})\end{array}$ & $\begin{array}{c}\text { Slow shot } \\
\text { speed }\left(\mathrm{m} \cdot \mathrm{s}^{-1}\right)\end{array}$ & $\begin{array}{c}\text { Fast shot } \\
\text { speed }\left(\mathrm{m} \cdot \mathrm{s}^{-1}\right)\end{array}$ & $\begin{array}{c}\text { Intensification } \\
\text { pressure }(\mathrm{MPa})\end{array}$ \\
\hline 953 & 453 & 0.15 & 5.0 & 13.7 \\
\hline
\end{tabular}




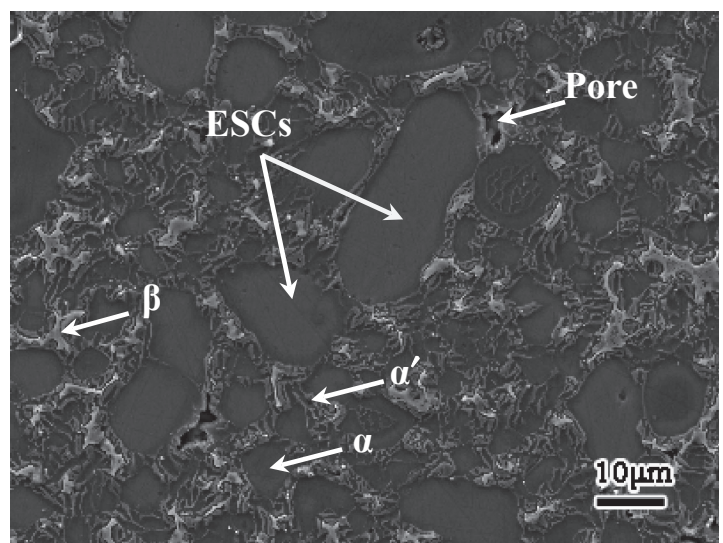

Fig. 4 Typical SEM micrograph in specimens showing the microstructural features in the as-cast AZ91D alloy produced by vacuum die casting process.

It can be seen that the microstructure is composed of ESCs, pores, secondary $\alpha$-Mg particles $(\alpha)$ and net-like divorced eutectics distributed in the grain boundaries. In the divorced eutectics, the discrete $\beta-\mathrm{Mg}_{17} \mathrm{Al}_{12}$ particles $(\beta)$ are surrounded by the supersaturated $\alpha-\mathrm{Mg}$ solution $\left(\alpha^{\prime}\right)$. The secondary $\alpha$ $\mathrm{Mg}$ particles are nearly spherical with a size less than $10 \mu \mathrm{m}$ in diameter, much smaller than those of the ESCs. The formation of this fine grain microstructure is caused by the quick cooling after the liquid metal was inserted into the die cavity during the vacuum die casting process. The secondary $\alpha$-Mg particles are supersaturated slightly, and have a little higher $\mathrm{Al}$ content when compared to the ESCs. ${ }^{20)}$ Figure 5 shows the distribution of $\mathrm{Mg}$ and $\mathrm{Al}$ elements along the grain boundary in the as-cast AZ91D alloy. The results demonstrate that the Al element in AZ91D alloy is concentrated to the grain boundaries, while the $\alpha-\mathrm{Mg}$ particles have low $\mathrm{Al}$ contents and the $\mathrm{Al}$ element is uniformly distributed in them.

\subsection{Microstructural evolution during the early stage of solution treatment}

There was no significant change on the grain sizes after solution treatment for $15 \mathrm{~min}$. Figure 6 shows the microstructure and the EDS line scan results along the grain boundary in the central region on the casting cross section of
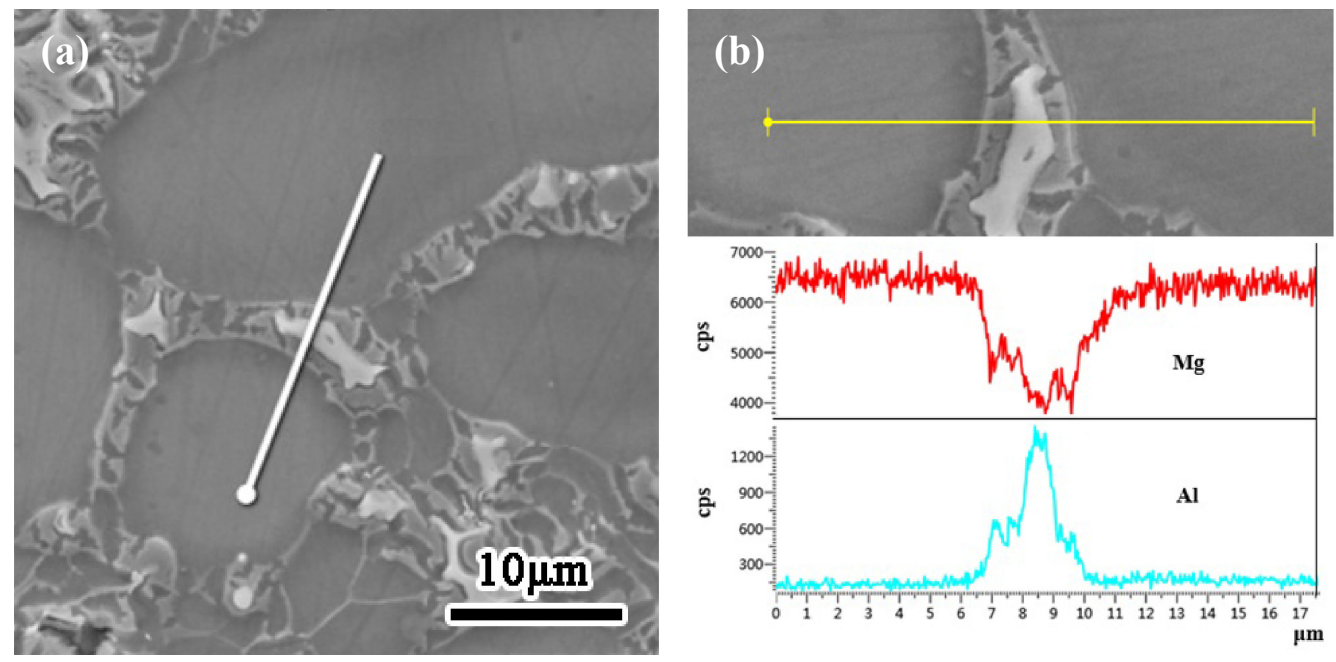

Fig. 5 Microstructure and the distribution of $\mathrm{Mg}$ and $\mathrm{Al}$ elements along the grain boundary in the as-cast AZ91D alloy produced by vacuum die casting process: (a) SEM micrograph, (b) EDS line scan.
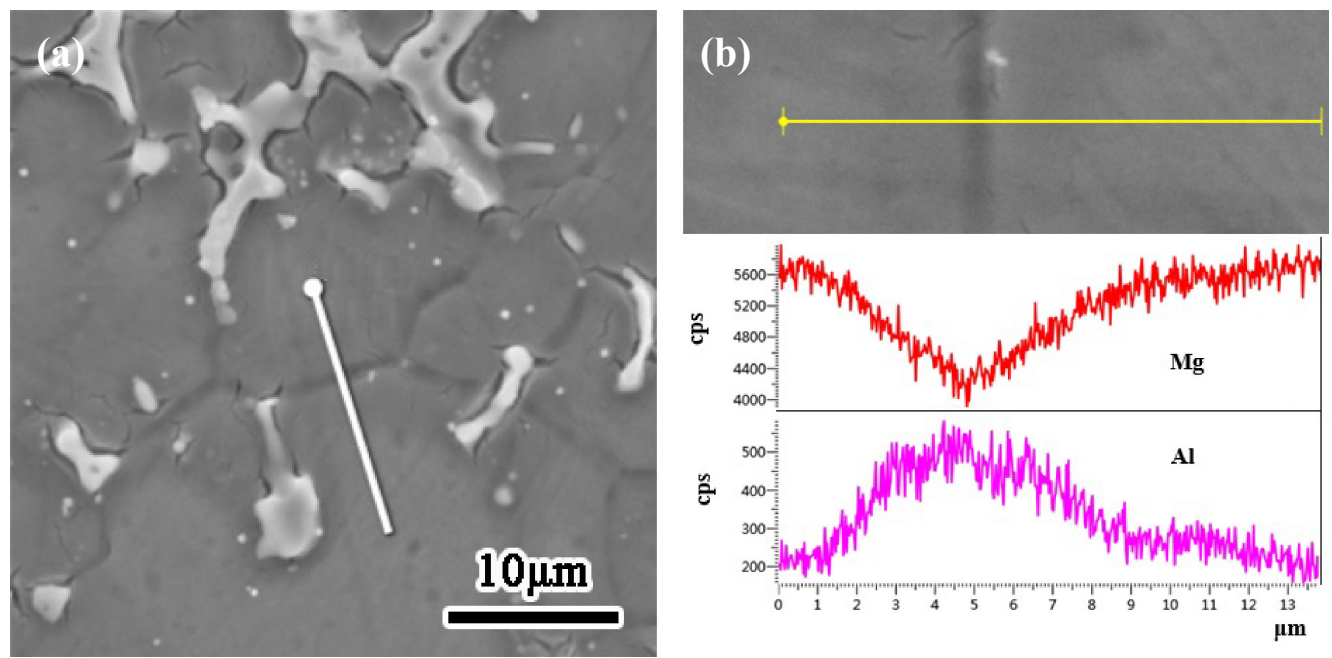

Fig. 6 Microstructure and the distribution of $\mathrm{Mg}$ and $\mathrm{Al}$ elements along the grain boundary in the vacuum die cast AZ91D alloy after solution treatment for 15 min: (a) SEM micrograph, (b) EDS line scan. 

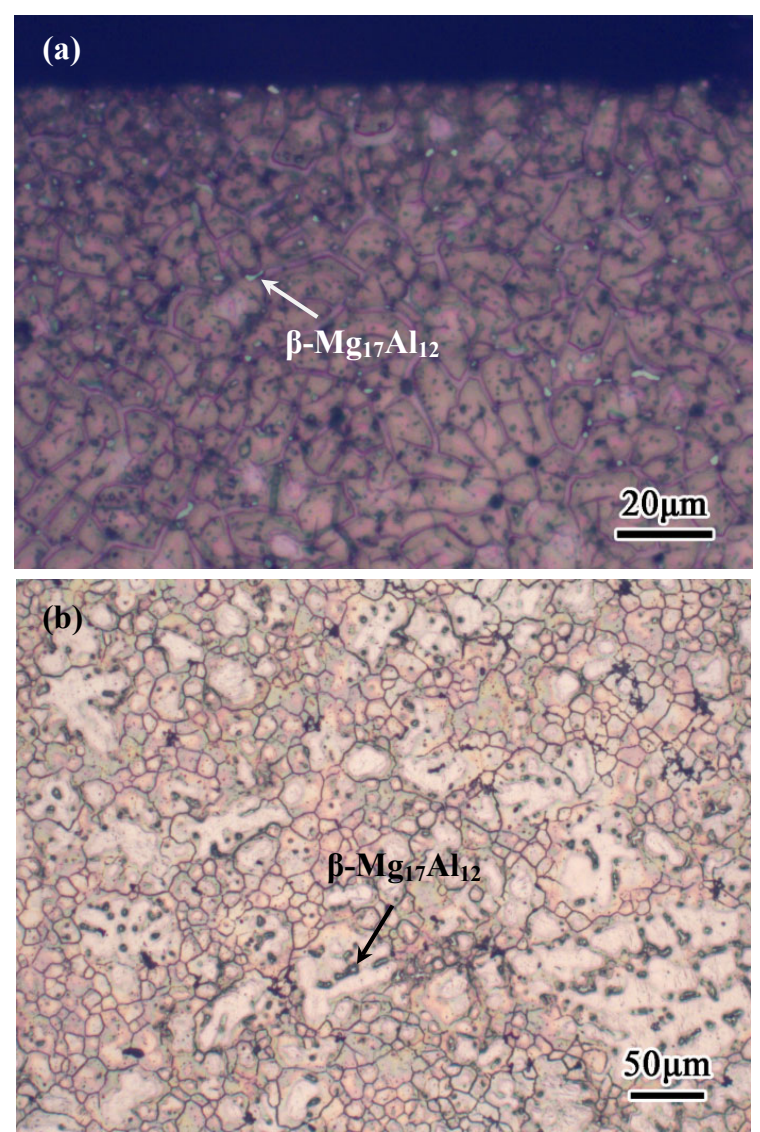

Fig. 7 Optical micrographs taken from different regions on the casting cross section after solution treatment for $30 \mathrm{~min}$ : (a) the surface layer, (b) the central region.

the vacuum die castings after solution treatment for $15 \mathrm{~min}$. In contrast to the as-cast microstructure (Figs. 4 and 5), no supersaturated $\alpha-\mathrm{Mg}$ solution exist in the grain boundaries, and the $\alpha-\mathrm{Mg}$ grains are well defined by sharp boundaries. The EDS line scan results display that the distributions of $\mathrm{Al}$ element in the $\alpha-\mathrm{Mg}$ particles are no more uniform, the closer to the grain boundaries, the higher the Al content will be. This indicates that the $\mathrm{Al}$ element concentrated in the grain boundaries has partially diffused into the $\alpha-\mathrm{Mg}$ particles, which caused the dissolution of the supersaturated $\alpha-\mathrm{Mg}$ solution originally distributed in the grain boundaries.

The dissolution of the $\beta-\mathrm{Mg}_{17} \mathrm{Al}_{12}$ particles also took place at the early stage of solution treatment. Figure 7 shows the microstructure in different regions on the casting cross section after solution treatment for $30 \mathrm{~min}$. To identify the remaining $\beta$ phase, the color metallographic technique was employed. The light gray particles are $\beta-\mathrm{Mg}_{17} \mathrm{Al}_{12}$. It is found that there are some $\beta-\mathrm{Mg}_{17} \mathrm{Al}_{12}$ particles remain undissolved in both regions, but the remaining $\beta$ phase has different distribution locations. The remaining $\beta-\mathrm{Mg}_{17} \mathrm{Al}_{12}$ particles are dispersively distributed in the grain boundaries in the surface layer (Fig. 7(a)), while in the central region, the vast majority of the remaining $\beta-\mathrm{Mg}_{17} \mathrm{Al}_{12}$ particles are distributed in the relatively large grains, only a few $\beta-\mathrm{Mg}_{17} \mathrm{Al}_{12}$ particles exist in the grain boundaries (Fig. 7(b)). This difference is due to the different diffusion speeds of Al element at different locations. The fine grain microstructure in the surface layer is a secondary solidified structure. According to Lee et al., ${ }^{21)}$ inverse macro-segregation would take place in the surface layer in HPDC process. After the liquid metal with primary grains (ESCs) was inserted into the die cavity, the solidification began at the surface of the casting. A local contraction would occur, which could draw the solute rich liquid present in the inter-dendritic channels to the surface of the casting, producing high concentration of solute elements at the casting surface. The inverse macro-segregation caused a relatively higher $\mathrm{Al}$ content in the surface layer of the castings. Besides, the surface layer has a much smaller mean grain size when compared to the central region. The uniform distribution of $\mathrm{Al}$ element in a small grain can be quickly achieved due to the relatively short diffusion distance. These two facts can effectively restrict the solute diffusion in the surface layer. That is why some $\beta-\mathrm{Mg}_{17} \mathrm{Al}_{12}$ particles can be found in the grain boundaries in the surface layer when the $\beta$ phase located in the grain boundaries in the central region has almost completely dissolved. In the central region, as well known, the diffusion speed of $\mathrm{Al}$ element inside $\alpha-\mathrm{Mg}$ grains is much slower than that in the grain boundaries, resulting in that many $\beta-\mathrm{Mg}_{17} \mathrm{Al}_{12}$ particles encapsulated in the relatively large grains remain undissolved after solution treatment for $30 \mathrm{~min}$.

The relatively large grains contain $\beta-\mathrm{Mg}_{17} \mathrm{Al}_{12}$ particles (Fig. 7(b)) evolved from the ESCs in the as-cast AZ91D alloy (Fig. 3). It can be seen clearly that the ESCs have experienced great changes during the early stage of solution treatment. Figure 8 shows the microstructure and the distribution of $\mathrm{Mg}, \mathrm{Al}$ and $\mathrm{Zn}$ elements in a relatively large grain which contains a rosettelike halo in the middle. As shown in Fig. 8, the rosettelike halo has relatively lower $\mathrm{Al}$ content in the grain. According to Wang et al., ${ }^{16)}$ the formation of these halos is caused by the insufficient diffusion of the $\mathrm{Al}$ element. We can confirm that this relatively large grain evolved from one of the rosettelike ESCs shown in Fig. 9. The brighter particles with high Al contents are undissolved $\beta$-phase. These remaining $\beta$ $\mathrm{Mg}_{17} \mathrm{Al}_{12}$ particles were originally located in the grain boundaries in the as-cast AZ91D alloy as shown in Fig. 4. The formation of this microstructural feature can be explained as follows. The ESCs start to grow with the diffusing of $\mathrm{Al}$ atoms from the secondarily solidified structures into them. After the dissolution of the supersaturated $\alpha-\mathrm{Mg}$ solution originally distributed in the grain boundaries, the growing dendrite arms of the rosettelike ESC would get in touch with the neighbouring ones. Considering that the dendrite arms of an ESC have the same crystal orientation, the neighbouring dendrite arms are prone to merge together at the contact points. During this period, some $\beta$ - $\mathrm{Mg}_{17} \mathrm{Al}_{12}$ particles dispersively distributed between the dendrite arms remain undissolved and they would be encapsulated in the relatively large $\alpha-\mathrm{Mg}$ grain. The mergence of neighbouring dendrite arms and further growth produce a relatively large $\alpha$-Mg grain with near globular morphology.

In contrast to the central region, no significant grain growth can be observed in the surface layer of the vacuum die castings after $30 \mathrm{~min}$ solution treatment. As shown in Fig. 7(a), the fine grains with sizes less than $10 \mu \mathrm{m}$ in diameter are well defined by sharp boundaries. This can be 


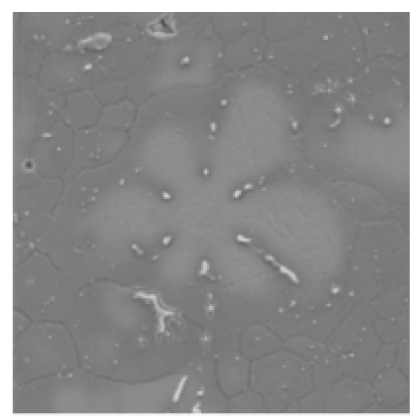

$\longdiv { 2 5 \mu \mathrm { m } }$

Mg Ka1_2

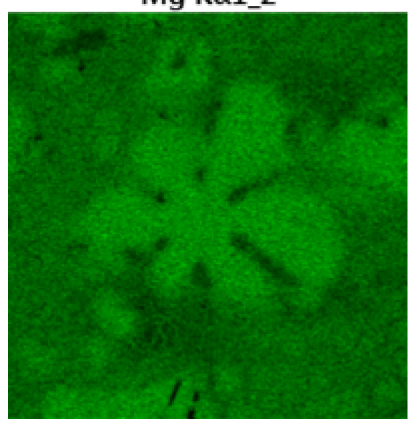

Al $K \alpha 1$

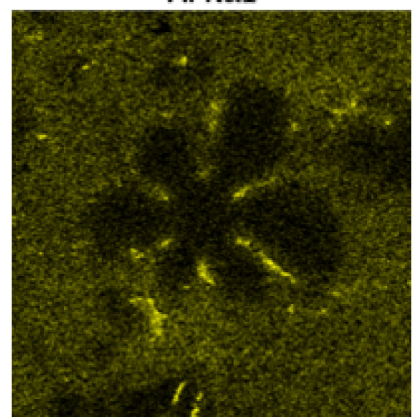

Zn L $\alpha 12$

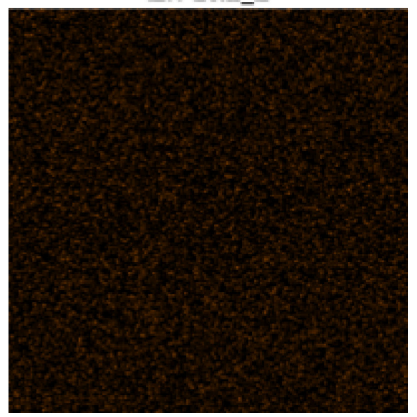

Fig. 8 Surface scanning images taken from the central region showing the microstructure and the distribution of $\mathrm{Mg}, \mathrm{Al}$ and $\mathrm{Zn}$ elements in a small area containing a rosettelike halo in the vacuum die castings after solution treatment for $30 \mathrm{~min}$.

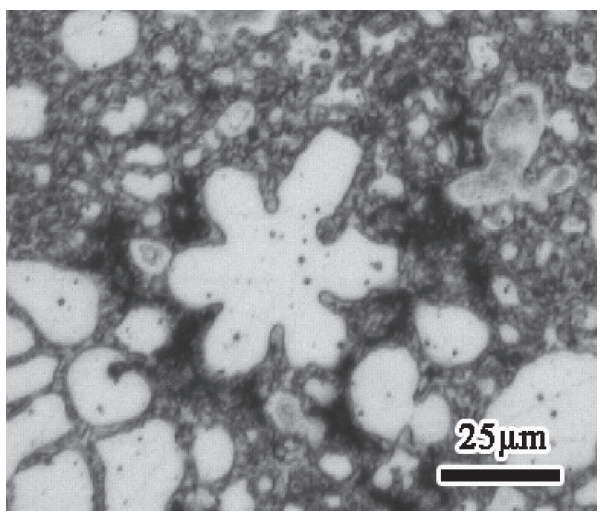

Fig. 9 Microstructural features of a rosettelike ESC in the as-cast AZ91D alloy produced by vacuum die casting process. attributed to the remaining $\beta-\mathrm{Mg}_{17} \mathrm{Al}_{12}$ particles dispersively distributed in the grain boundaries as shown in Fig. 7(a). These undissolved $\beta-\mathrm{Mg}_{17} \mathrm{Al}_{12}$ particles have an effect of restraining the grain growth in the surface layer.

After solution treated for $40 \mathrm{~min}$, the $\beta$-phase in the vacuum die castings has completely dissolved into the $\alpha-\mathrm{Mg}$ grains, as shown in Fig. 10. The fine grain microstructure in the surface layer has been destroyed. Similarly to the central region, some relatively large grains with near globular morphology can be observed in the surface layer. The difference is that, most of the relatively large grains in the surface layer do not contain the halo structure, which means that these relatively large grains are not evolved from the ESCs. They are formed due to the abnormal growth of the fine grains driven by the interface energy. It is also found in Fig. 10(b) that, up to $40 \mathrm{~min}$ solution time, some halos in the relatively large grains still maintained the morphology of the ESCs, e.g. rosettelike.
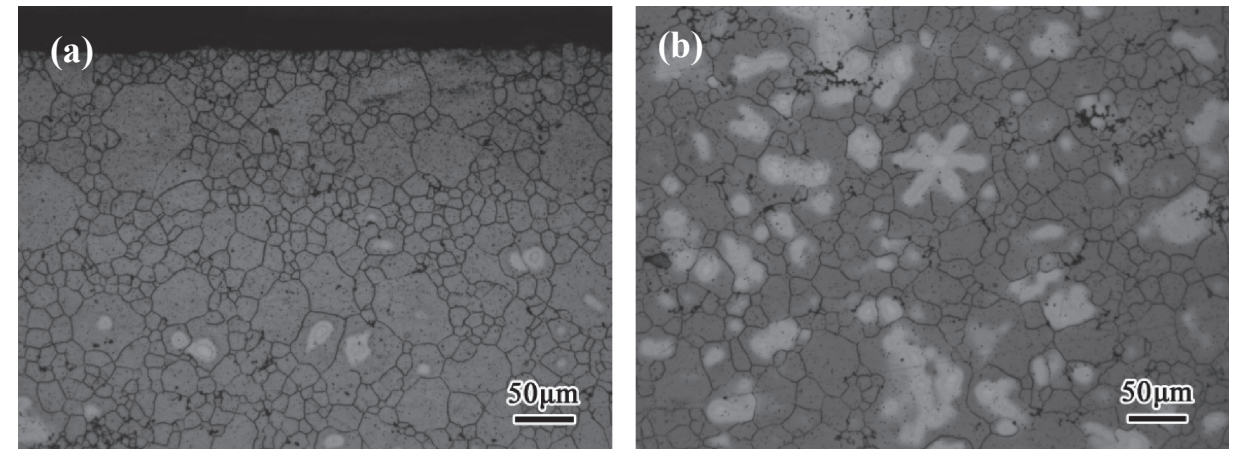

Fig. 10 Optical micrographs taken from different regions on the casting cross section after solution treatment for 40 min: (a) the surface layer, (b) the central region. 

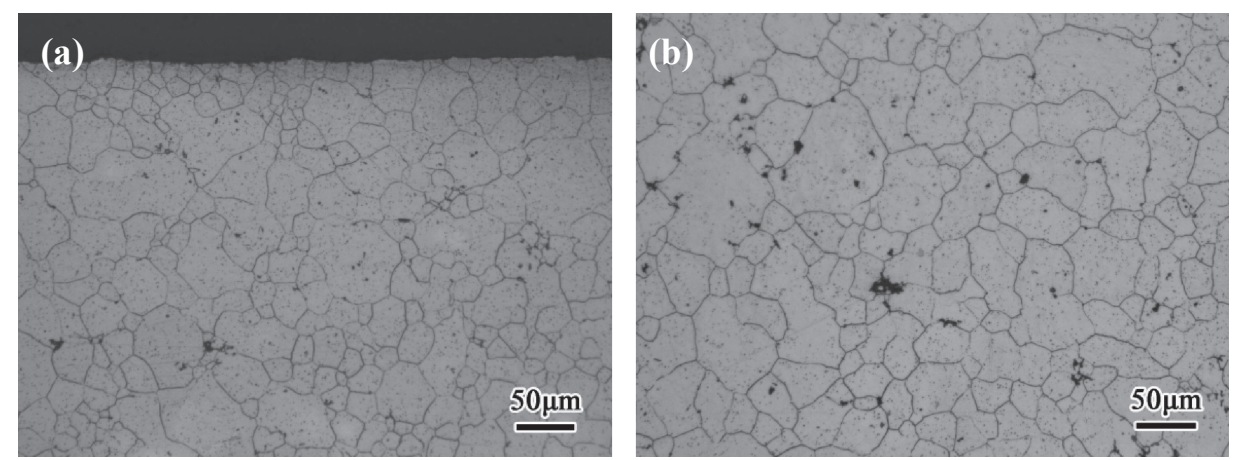

Fig. 11 Optical micrographs taken from different regions on the casting cross section after solution treatment for $20 \mathrm{~h}$ : (a) the surface layer, (b) the central region.

After 40 min solution treatment, the mean grain size in the surface layer was measured to be $13.4 \mu \mathrm{m}$, much smaller than $22.2 \mu \mathrm{m}$ measured in the central region. The grain size distribution in the two regions are shown in Fig. 12. There are apparently two peaks in the distribution curves for the central region, indicating the difference in grain size for the fine grains and the relatively large grains evolved from ESCs. In comparison, for the surface layer, only a large peak appears at a small grain size less than $10 \mu \mathrm{m}$, the relatively large grains account for only a small part, resulting in a smaller mean grain size in the surface layer than that in the central region.

\subsection{Microstructural features in different regions of the vacuum die castings after the solution treatment}

Figure 11 shows the microstructures in different regions on the casting cross section after the solution treatment (treated at $413^{\circ} \mathrm{C}$ for $20 \mathrm{~h}$ ). No Al-rich halos can be found, which means that the time of the solution treatment was sufficient for the diffusion of $\mathrm{Al}$ element. The mean grain size in the surface layer and the central region has increased to 26.7 and $33.7 \mu \mathrm{m}$, respectively. Figure 12 shows the grain size distribution in the two regions after the solution treatment. It can be seen that, for the surface layer the peak shifts from 8 to $18 \mu \mathrm{m}$, and for the central region the peak appearing at the smaller grain size shifts from 12 to $27 \mu \mathrm{m}$, as the solution treatment time increases from $40 \mathrm{~min}$ to $20 \mathrm{~h}$. This growth of fine grains was apparently driven by the interface energy, and it should take the major responsibility for the increase of the mean grain size in both regions.

Figure 13 shows the microstructure of the segregation band in specimens after the solution treatment. In contrast to the surface and central regions, the segregation band has not experienced significant grain growth. The great majority of $\alpha-\mathrm{Mg}$ grains located in the segregation band have still maintained a size less than $10 \mu \mathrm{m}$ in diameter. It can be seen clearly that the fine grains are surrounded by the shrinkage porosities concentrated in the segregation band. Apparently, the shrinkage porosities could effectively restrain the grain growth, resulting in the survival of the fine grain microstructure in the segregation band.

\section{Conclusions}

(1) The supersaturated $\alpha-\mathrm{Mg}$ solution located in the grain
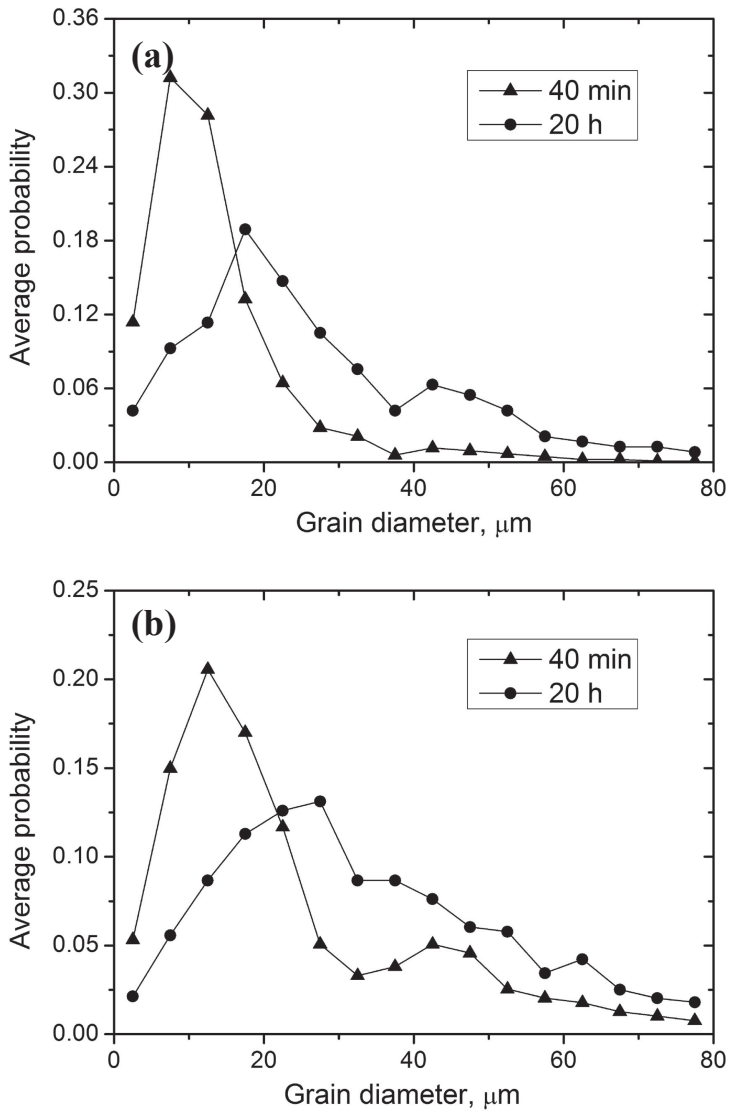

Fig. 12 Grain size distribution in different regions on the casting cross section after solution treatment for $40 \mathrm{~min}$ and $20 \mathrm{~h}$ : (a) the surface layer, (b) the central region.

boundaries first dissolved during solution treatment.

(2) In the central region, the diffusion of Al element caused the ESCs grew into relatively large $\alpha-\mathrm{Mg}$ grains with near globular morphology, during which some $\beta$ $\mathrm{Mg}_{17} \mathrm{Al}_{12}$ particles were encapsulated in the relatively large $\alpha-\mathrm{Mg}$ grains due to the mergence of neighbouring dendrite arms of the same ESC.

(3) The diffusion speed of $\mathrm{Al}$ element in the surface layer was slower than that in the central region, resulting a slower dissolution speed for the $\beta-\mathrm{Mg}_{17} \mathrm{Al}_{12}$ particles distributed in the grain boundaries in the surface layer. These undissolved $\beta$ - $\mathrm{Mg}_{17} \mathrm{Al}_{12}$ particles could effectively restrain the grain growth in the surface layer driven by the interface energy. 


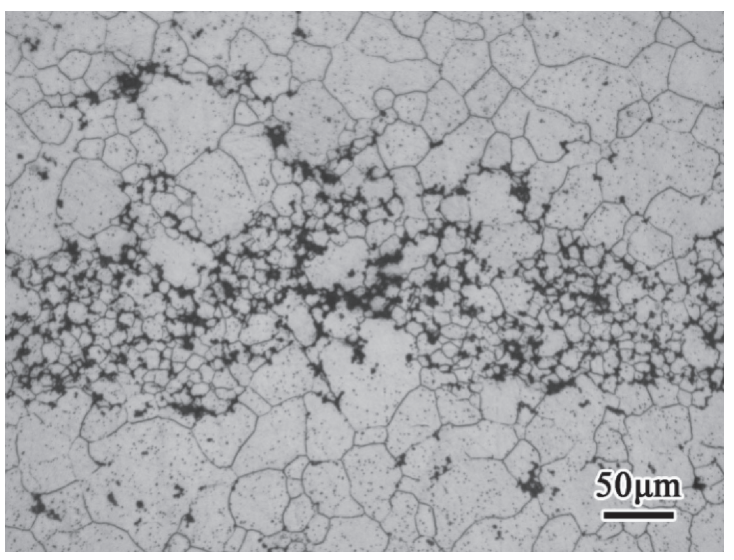

Fig. 13 Optical micrograph showing the microstructural features of the segregation band in specimens after the solution treatment.

(4) In contrast to the surface and central regions, the fine microstructure in the segregation band survived after the solution treatment. This could be attributed to the hindering effect on the grain growth of the shrinkage porosities concentrated in the segregation band.

\section{Acknowledgments}

The authors gratefully acknowledge the financial supports from Hebei Province Science Foundation for Youths (Grant No. E2017203104), Doctoral Scientific Fund Project of Yanshan University (Grant No. B917) and Science and Technology Research Foundation for Colleges and Universities of Hebei Province (Grant No. QN2018164).

\section{REFERENCES}

1) S. Schumann and H. Friedrich: Mater. Sci. Forum 419-422 (2003) 5156.

2) I.J. Polmear: Mater. Sci. Technol. 10 (1994) 1-16.

3) W.H. Sun, X.Y. Shi, E. Cinkilic and A.A. Luo: J. Mater. Sci. 51 (2016) 6287-6294.

4) K.V. Yang, M.A. Easton and C.H. Caceres: Mater. Sci. Eng. A 580 (2013) 191-195.

5) C.M. Gourlay and A.K. Dahle: Nature 445 (2007) 70-73.

6) C.M. Gourlay, H.I. Laukli and A.K. Dahle: Metall. Mater. Trans. A 38 (2007) 1833-1844.

7) Z.W. Chen: Mater. Sci. Eng. A 348 (2003) 145-153.

8) S. Otarawanna, C.M. Gourlay, H.I. Laukli and A.K. Dahle: Mater. Chem. Phys. 130 (2011) 251-258.

9) E.J. Vinarcik: Adv. Mater. Process. 159 (2001) 49-50.

10) Y. Lu, F. Taheri, M.A. Gharghouri and H.P. Han: J. Alloy. Compd. 470 (2009) 202-213.

11) X.P. Niu, B.H. Hu, I. Pinwill and H. Li: J. Mater. Process. Technol. 105 (2000) 119-127.

12) M. Uchida: China Foundry 6 (2009) 137-144.

13) Y. Wang, G. Liu and Z. Fan: Acta Mater. 54 (2006) 689-699.

14) G.Y. Yuan, G.Q. You, S.L. Bai and W. Guo: J. Alloy. Compd. 766 (2018) 410-416

15) J. Song and S.M. Xiong: J. Alloy. Compd. 509 (2011) 1866-1869.

16) X.J. Wang, S.M. Zhu, M.A. Easton, M.A. Gibson and G. Savage: Int. J. Cast Met. Res. 27 (2014) 161-166.

17) K. Sadayappan, W. Kasprzak, Z. Brown, L. Ouimet and A.A. Luo: Mater. Sci. Forum 618-619 (2009) 381-386.

18) D.G. Leo Prakash and D. Regener: J. Alloy. Compd. 467 (2009) 271277.

19) H.I. Laukli, C.M. Gourlay and A.K. Dahle: Metall. Mater. Trans. A 36 (2005) 805-818.

20) Q.L. Wang, S.M. Xiong and X.Z. Zhang: Mater. Trans. 58 (2017) 3945.

21) S.G. Lee, G.R. Patel and A.M. Gokhale: Scr. Mater. 52 (2005) $1063-$ 1068. 